\title{
Dyssynergia cerebellaris myoclonica (Ramsay Hunt syndrome): a condition unrelated to mitochondrial encephalomyopathies
}

\author{
C A TASSINARI,* R MICHELUCCI,* P GENTON, $\dagger$ J F PELliSSIER, $\ddagger$ J ROGER $\dagger$ \\ From the Neurological Clinic, ${ }^{*}$ University of Bologna School of Medicine, Bologna, Italy, Center Saint-Paul, $\dagger$ \\ and Laboratory of Neuropathology, $\ddagger$ School of Medicine, Marseille, France
}

SUMMARY Thirteen patients with dyssynergia cerebellaris myoclonica (Ramsay Hunt syndrome) had full clinical and neurophysiological study as well as muscle biopsy. The patients had action myoclonus, generalised epileptic seizures, and mild cerebellar syndrome. The disease was inherited in an autosomal recessive pattern in five patients, and occurred as isolated cases in the remaining eight patients. The age at onset of symptoms ranged from 6 to 15 years (mean, 10.4 years). The EEG and polygraphic findings included normal background activity in most patients, spontaneous fasf generalised spike-and-wave discharges, photosensitivity, no activation during slow sleep, and verte 8 and rolandic spikes in REM sleep. Results of muscle biopsy, performed an average of 14 years afteB onset of the disease, were normal and showed no mitochondrial abnormalities. These findings sugges that Ramsay Hunt syndrome is a condition with distinctive clinical and neurophysiological features and unrelated to mitochondrial encephalomyopathies.

Dyssynergia cerebellaris myoclonica (DCM), or Ramsay Hunt syndrome, is a rare disorder of unknown aetiology characterised by action or intention myoclonus with cerebellar signs and epilepsy. ${ }^{1-3}$ Despite the scarcity of anatomical verification, the most commonly reported pathological change is degeneration of the olivodentatorubral system. ${ }^{24}$ The nosological place of DCM is still unclear; Ramsay Hunt syndrome has been classified under spinocerebellar degenerations $^{5}$ and referred to as a form of progressive myoclonic epilepsy. ${ }^{36}$

A condition in which action myoclonus and epilepsy were associated with a mitochondrial myopathy, as demonstrated by muscle biopsy, was first described by Spiro et $a l^{7}$ and Tsairis $e t a l^{8}$ and subsequently by many others. ${ }^{9-24}$ This condition, also defined as myoclonic epilepsy with ragged red fibres MERRF, ${ }^{12}$ was

Address for reprint requests: Carlo Alberto Tassinari, Neurological Clinic, University of Bologna School of Medicine, Via Ugo Foscolo 7, 40123 Bologna, Italy.

Received 31 May 1988 and in revised form 10 October 1988. Accepted 17 October 1988 considered to bear many clinical similarities to DCM, ${ }^{121325}$ or even to account for most or all such cases of DCM.24

This report describes the clinical and neurophysiological study, with muscle biopsy, of 13 patients with DCM. The aim of the study was to verify the existence of abnormal mitochondria in the skeletal muscle of patients with DCM and, from the findings in these patients and a review of the available literature on MERRF, to determine if there are any significant differences between the two conditions.

\section{Patients and results}

Thirteen patients with DCM (five females and eight males, aged 13 to 48 years) were studied; four were observed at the Neurological Clinic in Bologna and nine at the Center SaintPaul in Marseille.

\section{Clinical findings}

The disease occurred as isolated cases in eight patients, and five patients had siblings with DCM. None of the parents had DCM. The parents of six patients were consanguineous. Three patients had a positive family history of epilepsy. 
The age at onset of the disease ranged from 6 to 15 years (mean, $10 \cdot 4$ years). The first symptoms were epileptic seizures (clonic, four patients; myoclonic, three patients; tonic-clonic, two patients; absences, one patient) in 10 patients, action myoclonus in two patients, and cerebellar symptoms in one patient. In all patients, the complete clinical picture included epileptic seizures (clonic, 12 cases; myoclonic, 11 cases; tonicclonic, 10 cases; absences, three cases) and action or intention myoclonus.

A mild cerebellar syndrome was present in 11 patients. Other findings included pes cavus (three patients), hypopallaesthesia of the lower limbs (two patients), and scoliosis (one patient). Mild intellectual impairment was verified in four patients. The results of funduscopic examination were normal. In all patients, the seizures responded to treatment with sodium valproate or benzodiazepines and diminished in frequency or disappeared with evolution of the disease. Myoclonus was improved or unmodified by treatment in six patients and worsened in seven patients. There was slow deterioration of the cerebellar syndrome in four patients. The mild mental defect verified in four cases did not progress during the course of the illness. Intellect was preserved in the remaining patients over a long term followup period.

At the time of our observations, which were made an average of 16.9 years (range, 7.5 to 37 years) after the onset of the disease, a 32 year old patient who had been affected for 20 years was bedridden, five patients needed help with activities of daily living, and seven patients were only minimally affected and could live without assistance.

\section{Neurophysiological findings}

Waking EEG records. Background activity in the waking EEG was normal in seven patients and moderately slow in six. Spontaneous brief bursts of fast generalised spike-andwave discharges were recorded in all patients. The paroxysmal abnormalities were increased by intermittent photic stimulation in 11 patients.

Night sleep EEG records. Sleep polygraphic records showed generalised bursts of fast spike-and-wave discharges similar to those observed during wakefulness. During rapid eye movement (REM) sleep, fast polyspikes, localised in the central and vertex regions, appeared in 12 patients. Cyclic organisation of sleep was preserved.

Evoked potentials. Somatosensory evoked potentials were recorded in 10 patients, and the amplitude was increased (up to $50 \mu \mathrm{V}$ ) for the $\mathrm{P}_{25}-\mathrm{N}_{30}$ component in eight patients. Highvoltage late components were observed in three of five patients in whom visual evoked potentials were recorded.

Electromyography. Electromyography with determination of motor and sensory conduction velocities was performed in six patients, and the results were all normal.

\section{Pathological findings}

Biopsy of muscle (deltoid, four patients; quadriceps femoris, six patients; tibialis anterior, two patients; biceps brachii, one patient) was done in all patients an average of 14.2 years (range, 5.5 to 37 years) after the onset of the disease. Light and electron microscopic examinations of the biopsy specimens did not reveal any significant changes. The results of histochemical analysis of the specimens were also normal. Measurement of enzymes in the mitochondrial respiratory chain in four patients showed no abnormalities. Lafora bodies were not found.
Computed tomography and clinical laboratory findings

Computed tomography (CT) of the skull was performed in nine patients; except for cerebellar atrophy in one, the scans showed no abnormalities. The results of routine blood and urine tests were normal. Repeated measurement of serum lactate and pyruvate yielded normal values. Activity of lysosomal enzymes in white cells was normal, as was excretion of mucopolysaccharides and oligosaccharides in the urine.

\section{Discussion}

The most conspicuous clinical features noted in these 13 patients were action myoclonus, generalised epileptic seizures, and a mild, slowly progressive cerebellar syndrome. There was autosomal recessive inheritance in five patients. The disease invariably began in childhood or early adolescence. The associated EEG and polygraphic findings included normal background activity (in seven patients), spontaneous fast generalised spike-and-wave discharges, photosensitivity, no activation during slow sleep, and vertex and rolandic spikes in REM sleep. The amplitude of somatosensory evoked potentials was very exaggerated, as previously found in DCM. ${ }^{26}$ These clinical and neurophysiological findings, summarised in the table, fit the diagnosis of DCM (Ramsay Hunt syndrome) defined in accordance with the clinical and EEG criteria proposed by Roger $e t$ $a l^{27}$ and Tassinari et al. ${ }^{28}$

Muscle changes have not been reported in Ramsay Hunt syndrome, and muscle biopsy specimens from our patients were normal and did not reveal any mitochondrial abnormalities. In MERRF, however, there is evidence of abnormal mitochondria in skeletal muscle; this recently recognised clinical entity is also characterised by myoclonus, cerebellar syndrome, epilepsy, and a variety of neurological and extraneurological signs. ${ }^{12}$

Berkovic et al $^{24}$ found mitochondrial myopathy in nine patients (six from the same family) previously diagnosed as having DCM; they stated that "Ramsay Hunt syndrome is no longer a useful diagnostic category" and "it is largely (or) completely accounted for by the mitochondrial encephalomyopathies."

In the table, the clinical and EEG features of 26 reported cases of MERRF are compared with the findings from our cases of DCM. It is evident that MERRF differs from DCM in the following respects: 1. In MERRF, the inheritance is usually autosomal dominant or maternal, but in many DCM cases, it is autosomal recessive.

2. The age at onset of clinical symptoms is quite variable in MERRF, ranging from early childhood to adulthood; in DCM, it is restricted to childhood or early adolescence.

3. The triad of myoclonus, cerebellar syndrome, and 
Tassinari, Michelucci, Genton, Pellissier, Roger

Table Clinical and EEG features of dyssynergia cerebellaris myoclonica (DCM) and myoclonic epilepsy with ragged red fibres (MERRF)

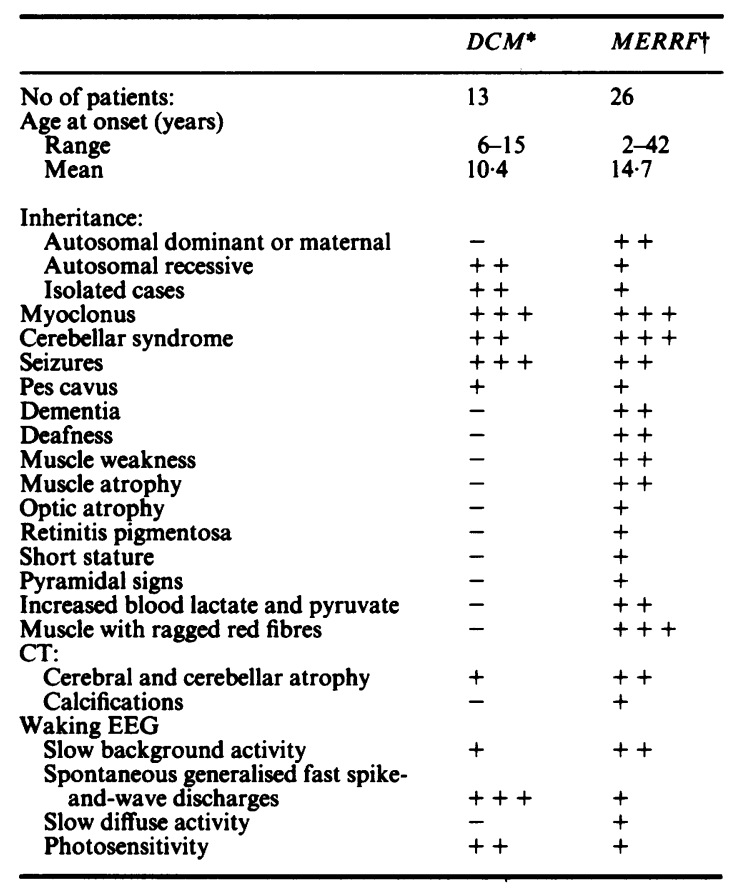

*Cases from present series.

†Cases from literature review. ${ }^{-23}$

Key: +++ always present, ++ very frequently present, + present in some cases, - not present (not observed in cases reported to date).

generalised epileptic seizures is found in both conditions. In MERRF, however, a constellation of other neurological signs and multisystem abnormalities is usually encountered in various combinations, including the frequent occurrence of deafness, dementia, muscle weakness and atrophy, and ocular abnormalities. It should be emphasised that no case of MERRF has been reported without an additional clinical sign (dementia, deafness, or weakness) associated with the classic triad. In contrast, DCM is devoid of neurological signs other than myoclonus, epilepsy, and cerebellar syndrome.

4. The EEG features of MERRF have been scarcely studied, and only one patient has had a night sleep polygraphic study.$^{15}$ The background activity, which is normal or slightly abnormal in DCM, is usually slow in MERRF with or without diffuse slow wave discharges (in the theta or delta range). Spontaneous spike-and-wave discharges have been observed in $100 \%$ of DCM cases, but in only $19 \%$ of MERRF cases. In addition, photosensitivity has been observed in $85 \%$ of DCM cases and $27 \%$ of MERRF cases.

5. The evolution of these two conditions is also different. Ramsay Hunt syndrome carries a relatively good prognosis with excellent seizure control and very® slow progression of the cerebellar syndrome and myoclonus. In our group, only one patient wase bedridden, and the remaining 12 were minimally orō moderately affected an average of 17 years after the $D$ onset of the disease. In MERRF, there is often rapid worsening of symptoms and the early occurrence of serious disability. Seven deaths have been reported in the MERRF group, all related to the disease. 91012161921. 6. Blood lactate and pyruvate levels are increased in most cases $(82 \%)$ of MERRF, but are normal inDCM.

7. Results of muscle biopsy in our patients with DCM were normal. Although some rare cases of "mitochon- $-\widehat{\Phi}$ drial encephalomyopathy" having normal muscle histology have been described, ${ }^{29}$ muscle biopsy demon- ${ }^{\infty}$ strates ragged red fibres and clear mitochondrial $\vec{\circ}$ abnormalities in all cases of MERRF.

The concept of progressive myoclonic epilepsy covers many distinct clinical entities, including DCM, MERRF, Baltic myoclonic epilepsy, cherry-red spoto myoclonus syndrome, Lafora's disease, and a variety i of other metabolic and genetically determined conditions. ${ }^{6}$ The Marseille study ${ }^{2728}$ and our curreftin observations demonstrate that DCM is a homogee $-\mathrm{N}$ eous condition characterised by onset in childhood aro early adolescence, autosomal recessive inheritan@, -

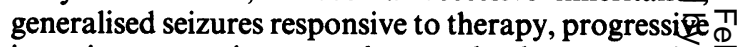
intention or action myoclonus, slowly progressige cerebellar syndrome, and typical EEG and potwgraphic findings. When these features are used 3 diagnostic criteria, DCM may be easily differentiated $\overrightarrow{0}$ from MERRF. MERRF is an often progressive and $\stackrel{0}{\circ}$ disabling condition with a wide spectrum of age at $\sigma$ onset, autosomal dominant or maternal inheritance, epilepsy, myoclonus, and cerebellar syndrome; it is associated with one or more additional neurological signs and distinctive laboratory and pathological $\frac{\mathrm{D}}{\mathrm{a}}$ findings. However, our study, while it provides $\stackrel{\varrho}{\rightrightarrows}$ sufficient data to differentiate DCM from MERRF, was not intended to discuss the clinical distinctions, if 3 any, between Ramsay Hunt syndrome and other forms of progressive myoclonic epilepsy of unknown aetiology such as Baltic myoclonus. ${ }^{35}$

The diagnosis of Ramsay Hunt syndrome has long? been considered controversial by many inves- $\frac{5}{3}$ tigators. ${ }^{35}$ Indeed, some cases labelled Ramsay Hunt syndrome are often heterogeneous with respect to the clinical features (age at onset, genetic origin, 2 associated symptoms) and the anatomical lesions 5 verified at necropsy. In the light of our findings, $\rightarrow$ however, it is possible that some cases of "DCM", in which the patients have autosomal dominant inheritance, ${ }^{30-33}$ deafness, ${ }^{33}{ }^{34}$ and other neurological abnormalities $^{3536}$ were true instances of mitochondrial $\mathcal{N}$ 
myopathy, but the pathological findings were not reported. The present study clearly demonstrates that Ramsay Hunt syndrome, as defined by our diagnostic criteria, ${ }^{2728}$ is a condition unrelated to mitochondrial encephalomyopathies.

We thank Dr N Bresolin, from the University of Milan, for performing the enzyme measurements in the mitochondrial respiratory chain, Drs M Moggio and G Pellegrini, from the University of Milan, for performing the light and electron microscopic study of muscle specimens from four patients, and $\mathrm{Mr} \mathrm{N}$ Muzzi, from the University of Bologna, for his helpful collaboration in the bibliographic research. We are also indebted to Mrs B J Hessie for her expert assistance in revising the manuscript.

This work was supported by the $40 \%$ funds distributed by the Italian Ministry of Education.

\section{References}

1 Hunt JR. Dyssynergia cerebellaris myoclonica-primary atrophy of the dentate system: a contribution to the pathology and symptomatology of the cerebellum. Brain 1921;44:490-538.

2 Roger J, Soulayrol R, Hassoun J. La dyssynergie cérébelleuse myoclonique (syndrome de Ramsay Hunt). Rev Neurol (Paris) 1968;119:85-106.

3 Lance JW. Action myoclonus, Ramsay Hunt syndrome, and other cerebellar myoclonic syndromes. In: Fahn S, Marsden CD, Van Woert MH, eds. Myoclonus, Advances in Neurology, vol 43. New York: Raven Press, 1986:33-55.

4 Bird TD, Shaw CM. Progressive myoclonus and epilepsy with dentatorubral degeneration: a clinicopathological study of the Ramsay Hunt syndrome. J Neurol Neurosurg Psychiatry 1978;41:140-9.

5 Marsden CD, Hallett M, Fahn S. The nosology and pathophysiology of myoclonus. In: Marsden CD, Fahn S, eds. Movement Disorders. London: Butterworths, 1982:196-248.

6 Roger J. Progressive myoclonic epilepsy in childhood and adolescence. In: Roger J, Dravet C, Bureau M, Dreifuss FE, Wolf P, eds. Epileptic Syndromes in Infancy, Childhood, and Adolescence. London: John Libbey Eurotext, 1985:302-10.

7 Spiro AJ, Moore SL, Prineas W, Strasberg PM, Rapin I. A cytochrome-related inherited disorder of the nervous system and muscle. Arch Neurol 1970;23:103-12.

8 Tsairis P, Engel WK, Kark P. Familial myoclonic epilepsy syndrome associated with skeletal muscle mitochondrial abnormalities. Neurology 1973;23:408.

9 Shapira Y, Cederbaum SD, Cancilla PA, Nielsen D, Lippe BM. Familial poliodystrophy, mitochondrial myopathy, and lactate acidemia. Neurology 1975;25:614-21.

10 Guggenheim MA, Stumpf DA. Familial metabolic disease with clinicopathological findings of both Leigh's disease and adulttype spinocerebellar degeneration. Ann Neurol 1977;2:264-5.

11 Niedermeyer E, Fineyre F, Riley T, Bird B. Myoclonus and the electroencephalogram. A review. Clin Electroencephalogr 1979;10:75-95.

12 Fukuhara N, Tokiguchi S, Shirakawa K, Tsubaki T. Myoclonus epilepsy associated with ragged red fibers (mitochondrial abnormalities): disease entity or a syndrome? J Neurol Sci 1980;47:117-33.

13 Fitzsimons RB, Clifton-Bligh P, Wolfenden WH. Mitochondrial myopathy and lactic acidaemia with myoclonic epilepsy, ataxia and hypothalamic infertility: a variant of Ramsay-Hunt syndrome? J Neurol Neurosurg Psychiatry 1981;44:79-82.

14 Morgan-Hughes JA, Hayes DJ, Clark JB, et al. Mitochondrial encephalomyopathies. Biochemical studies in two cases revealing defects in the respiratory chain. Brain 1982;105:553-82.

15 Roger J, Pellissier JF, Dravet C, Bureau-Paillas M, Arnoux M,
Larrieu JL. Dégénérescence spino-cérébelleuse-atrophie optique-épilepsie-myoclonies-myopathie mitochondriale. Rev Neurol (Paris) 1982;138:187-200.

16 Nakano T, Sakai H, Amano N, Yagishita S, Ito Y. An autopsy case of degenerative type myoclonus epilepsy associated with Friedreich's ataxia and mitochondrial myopathy. Brain Nerve (Tokyo) 1982;34:321-32.

17 Feit H, Kirkpatrick J, Van Woert MH, Pandian G. Myoclonus, ataxia, and hypoventilation: response to L-5-hydroxytryptophan. Neurology 1983;33:109-12.

18 Holliday PL, Climie ARW, Gilroy J, Mahmud MZ. Mitochondrial myopathy and encephalopathy: three cases-a deficiency of NADH-COQ dehydrogenase? Neurology 1983;33:1619-22.

19 Sasaki H, Kuzuhara S, Kanazawa I, Nakanishi T, Ogata T. Myoclonus, cerebellar disorder, neuropathy, mitochondrial myopathy, and ACTH deficiency. Neurology 1983;33:1288-93.

20 Riggs JE, Schochet SS, Fakadej AV, et al. Mitochondrial encephalomyopathy with decreased succinate-cytochrome c reductase activity. Neurology 1984;34:48-53.

21 Kuriyama M, Umezaki H, Fukuda $Y$, et al. Mitochondrial encephalomyopathy with lactate-pyruvate elevation and brain infarctions. Neurology 1984;34:72-7.

22 Rosing HS, Hopkins LC, Wallace DC, Epstein CM, Weidenheim $\mathrm{K}$. Maternally inherited mitochondrial myopathy and myoclonic epilepsy. Ann Neurol 1985;17:228-37.

23 Petty RKH, Harding AE, Morgan-Hughes JA. The clinical features of mitochondrial myopathy. Brain 1986;109:915-38.

24 Berkovic SF, Andermann F, Karpati G, Carpenter S, Andermann E, Shoubridge E. Mitochondrial encephalomyopathies: a solution to the enigma of the Ramsay Hunt syndrome. Neurology 1987;37(Suppl 1): 125.

25 Hopkins LC, Rosing HS. Myoclonus and mitochondrial myopathy. In: Fahn S, Marsden CD, Van Woert MH, eds. Myoclonus, Advances in Neurology, vol 43. New York: Raven Press, 1986:105-17.

26 Mauguiere F, Bard J, Courjon J. Les potentiels evoques somesthesiques precoces dans la dyssynergie cerebelleuse myoclonique progressive. Rev Electroencephalogr Neurophysiol Clin 1981;11:174-82.

27 Roger J, Genton P, Bureau M, Dravet C, Tassinari CA. Dyssynergia cerebellaris myoclonica (Ramsay Hunt's syndrome) associated with epilepsy: a study of 32 cases. Neuropediatrics 1987;18:117.

28 Tassinari CA, Bureau-Paillas M, Dalla Bernardina B, Grasso E, Roger J. Etude électroencéphalographique de la dyssynergie cérébelleuse myoclonique avec épilepsie (syndrome de RamsayHunt). Rev Electroencephalogr Neurophysiol Clin 1974;4: 407-28.

29 Dvorkin GS, Andermann F, Carpenter S, et al. Classical migraine, intractable epilepsy and multiple strokes: a syndrome related to mitochondrial encephalomyopathy. In: Andermann F, Lugaresi E, eds. Migraine and Epilepsy. London: Butterworths, 1987:203-32.

30 Kreindler A, Crighel I, Poilici I. Clinical and electroencephalographic investigations in myoclonic cerebellar dyssynergia. J Neurol Neurosurg Psychiatry 1959;22:232-7.

31 Gilbert GJ, McEntee WJ, Glaser GH. Familial myoclonus and ataxia. Pathophysiologic implications. Neurology 1963;13: 365-72.

32 Jakobs $\mathrm{H}$. Myoclonus and ataxia occurring in a family. $J$ Neurol Neurosurg Psychiatry 1965;28:272-5.

33 May DL, White HH. Familial myoclonus, cerebellar ataxia and deafness. Specific genetically-determined disease. Arch Neurol 1968;19:331-8.

34 Lance JW, Evans WA. Progressive myoclonic epilepsy, nerve deafness and spinal muscular atrophy. Clin Exp Neurol 1984;20:141-51.

35 Halliday AM. The clinical incidence of myoclonus. In: William D, ed. Modern Trends in Neurology, vol 4. London: Butterworths, 1967:69-105.

36 Smith NJ, Espir ML, Matthews WB. Familial myoclonic epilepsy with ataxia and neuropathy with additional features of Friedreich's ataxia and peroneal muscular atrophy. Brain 1978;101:461-72. 